\title{
The Nearer, the Better? The Impact of Cultural and Geographic Distance on Crowdfunding Project Attractiveness
}

\author{
Hui Fan $\mathbb{D}^{1},{ }^{1}$ Teng Gao $\mathbb{D}^{2,3}$ and Shuman Liu $\mathbb{i}^{4}$ \\ ${ }^{1}$ School of Economics and Management, Tongji University, Shanghai, China \\ ${ }^{2}$ School of Tourism and Exhibition, Hefei University, Hefei, China \\ ${ }^{3}$ Chaohu Research Center for Culture, Economic and Social Development, Hefei, China \\ ${ }^{4}$ Faculty of Business, Lingnan University, Hong Kong, China \\ Correspondence should be addressed to Teng Gao; gaoteng1963@163.com
}

Received 21 July 2021; Accepted 4 September 2021; Published 26 September 2021

Academic Editor: Wen-Tsao Pan

Copyright (c) 2021 Hui Fan et al. This is an open access article distributed under the Creative Commons Attribution License, which permits unrestricted use, distribution, and reproduction in any medium, provided the original work is properly cited.

\begin{abstract}
Information asymmetry between backers and project creators impedes the crowdfunding success. Consequently, creators usually rely on various information to alleviate information asymmetry. Particularly, the location information of both backers and creators embodies their geographic and cultural distance, which may affect crowdfunding project attractiveness. Whereas current literature almost ignores the role cultural distance in crowdfunding, this research focuses on the reward-based crowdfunding, so that it becomes salient to form the appreciation and judgment of the innovative, creative, or artistic nature of projects. Meanwhile, geographic distance is examined to join the debates between flat world hypothesis and home bias proposition. A series of econometric models are examined based on a sample of 264 fundraising projects collected from Kitckstarter.com through Python program. Results show that cultural distance exerts a U-shape effect, which initially impedes the crowdfunding performance but promote projects when large enough. Geographic distance generally exerts insignificant impact on crowdfunding performance. Furthermore, cultural and geographic distance exerts the asymmetric effects on experienced versus new backers. This article underscores the important implications of cultural distance on reward-based crowdfunding. By showing the differential effects of cultural and geographic distance on experience versus new backers, it empirically infers the social capital as the underlying mechanism.
\end{abstract}

\section{Introduction}

Crowdfunding refers to the efforts by entrepreneurial individuals and groups using the Internet to fund their cultural, social, and for-profit ventures by drawing on relatively small contributions from a relatively large number of individuals, without standard financial intermediaries [1]. Online crowdfunding platforms have become appealing channels for fundraising, and markets for crowdfunding have rapidly and significantly grown into a multibilliondollar industry worldwide [2]. Although seemingly promising, not all crowdfunding projects can attract the desired amount of funding [3]. Information asymmetry in crowdfunding is pervasive, so that potential backers lack substantive knowledge on both the capabilities or trustworthiness and the characteristics of the proposed initiations [4-6].
Accordingly, current literature has documented various signals that crowdfunding creators can adopt to alleviate the information asymmetry and finally attract potential backers. Some work on the project quality signals embodied in the project descriptions [1,6-11], creator-trustworthiness signals [8, 12-15], timing signals [16], founders' social capital [4], and product quality signals $[14,17]$. Some other researchers focus on the implicit information during the dynamic fundraising cycle, such as herding information among backers [5], creator-backer interaction [18], and information implied by contributing patterns of previous backers $[16,19,20]$.

This study aims to add to the pertinent literature by understanding whether and how the geographic and cultural distance between a creator and a backer influences the performance of crowdfunding projects. Geographic distance is salient due to the fact that, as the striking features, 
crowdfunding platforms remove geographic limitations but great geographic distance always exists between the creator and backers [19]. In offline investment context, home bias exists because geographic proximity reduces the cost associated with information acquisition, transaction, or monitoring (rational/economic causes) and engenders trust and overoptimism toward transaction partners or opportunities (behavioral causes) [19, 21-23]. The ubiquity of the Internet promotes a "flat world" hypothesis [24] because the aforementioned "home bias" [21] seems to become irrelevant in crowdfunding. Nevertheless, subsequent research on geographic distance reveals controversial findings, advocating either a negative effect $[21,25]$ or a positive effect $[1,26]$.

The cultural distance information contained in crowdfunding projects is also an important factor affecting the success or failure of crowdfunding projects. Burtch et al. [25] underscored the cultural fraction caused by cultural distance and revealed its detrimental effect on crowdfunding performance. However, every cloud has a silver lining. Cultural distance helps backers "go out of the box" and provides opportunities for individuals to learn about disparate concepts and ideas from different cultures. This is similar to what Lu et al. [27] posit that intercultural social interaction stimulates cultural learning to acquire new information and understand about the assumptions, beliefs, customs, norms, values, or language of another culture. Mollick [1] provides implicit evidence on a positive effect of geographic distance on crowdfunding projects that reflect the underlying cultural products of particular geographic areas.

To fully understand the effect of geographic and cultural distance on crowdfunding project performance, we choose Kickstarter.com for the empirical investigations, which is the leading reward-based crowdfunding platform in the United States and has provided more funding for artists than the National Endowment for the Arts [28]. Based on a sample of 264 fundraising projects, this article reveals the more complex effects of cultural and geographic distance than those identified in the previous research. Cultural distance has a U-shape relationship with crowdfunding project attractiveness. It initially discourages backers from supporting crowdfunding projects when relatively small; however, the larger cultural distance makes the creative ideas more appealing when large enough. Surprisingly, geographic distance does not play a significant role in attracting backers to contribute. Moreover, we empirically infer the social capital acquired and accumulated from the platform community as one plausible mechanism. Whereas the U-shape effect of cultural distance only exists for experienced backers, large geographic distance encourages experienced backers but discourages new backers.

This article provides three-folded contributions. First, it understands more thoroughly the role of cultural distance on crowdfunding performance, which has been mostly ignored by the literature [25]. Increasing cultural distance initially impedes the crowdfunding success and funding willingness, which is consistent with what Burtch et al. [25] advocate; however, when it enlarges to some extent, its impact turns to be positive. The U-shape relationship between the cultural distance and crowdfunding performance we have identified are innovative to the crowdfunding literature. By highlighting the salience of cultural background in evaluating creative ideas, we contend that backers make a complex tradeoff between the uncertainty and perceived creativity of projects.

Second, we show that the effects of geographic distance do not seem to be straightforward. Though it does not significantly impact the crowdfunding success or backers' contribution amount, it implicitly influences the backer composition. It encourages experienced backers but discourages new backers to contribute. Our findings speak to the controversial literature on the effect of geographic distance (i.e., the negative effect by Burtch et al. [25] and Lin and Viswanathan [21] or the positive effect by Kang et al. [26] and Mollick [1]) and support the "flat world" hypothesis [24], instead of the "home bias" proposition [21].

Third, the difference between the experienced and naive backers reveals that crowdfunding platforms can cultivate the internal social capital in the community, which enables experienced backers to make the tradeoff between the uncertainty and perceived creativity. Also, the insights on how cultural distance and geographic distance influence the backer composition are innovative; whereas, currently, literature mostly focuses on the crowdfunding success $[1,10]$, backers' contribution decisions $[17,20]$, or interest rate $[8,12]$.

\section{Literature Review and Hypotheses}

Usually, crowdfunding involves an open call on the Internetbased platform for financial resources in the form of donation, exchange for future products, or some other rewards [29]. Various crowdfunding platforms (such as Kickstarter, Kiva, or SellaBand) reduce market frictions associated with geographic distance [19]. Remarkably, people still confront with uncertainty and information asymmetry on the trustworthiness of fundraisers [5] or project quality [11, 30]. Thus, crowdfunding creators utilize various signals to alleviate information asymmetry and attract potential backers.

2.1. Various Signals to Enhance Crowdfunding Project Attractiveness. Current literature has investigated various signals that help reduce uncertainty and information asymmetry in the crowdfunding market. Researchers underscore the signaling value of informational and social cues that facilitate backers to judge the project quality or trustworthiness of borrowers. The information in the project description determines crowdfunding success, ranging from the voluntary self-disclosure to the more subtle such as spelling errors or linguistic style of the text $[1,6,9,10]$. Meanwhile, backers attend to many cues to judge the credibility of a borrowers, such as his popularity in his social network as indicated by his friendship or online word-ofmouth $[7,12]$ or simply his appearance attractiveness $[8,13]$. Moreover, crowdfunding success is vulnerable to social influence; thus, the information implied by the contributing patterns of previous backers' shapes subsequent backers' decisions $[5,16,19,20]$. 
The broad geographic dispersion of backers supports a "flat world" hypothesis [24]. Existing findings on the effect of geographic distance are far from conclusive. Geographic proximity may limit backers' potential to leverage social networks. For instance, Mollick [1] and Kang et al. [26] disclosed a positive effect of geographic distance in that large geographic distance signals the widely recognized project quality or reflects the underlying cultural products. However, Lin and Viswanathan [21] and Burtch et al. [25] demonstrated that backers still favor geographically proximate projects, supporting a "home bias" proposition.

Among the four basic types of crowdfunding posited by Mollick [1], the reward-based model fits well with creative crowdfunding projects undertaken by artists, musicians, filmmakers, inventors, and social enterprise. First, individuals supporting such projects receive a reward but not any financial incentives, returns, or repayment [7]. Second, the biggest difference lies in information asymmetry and uncertainty [18]. In the all-or-nothing game, project creators set a funding goal and receive the donations only if the goal is reached, and only after the project is successfully funded and implemented, the product described in the creative crowdfunding project will exist [1] and can enlarge information asymmetry between creators and backers in the crowdfunding markets. Third, people make judgment and funding decisions based on their appreciation of the "innovative," "creative," or "artistic" nature of the products, for which the cultural background becomes salient. Thus, we consider whether and how cultural and geographic distance influences crowdfunding project attractiveness, aiming to contribute to the existing literature as follows.

First, we underscore the role of cultural distance in the reward-based crowdfunding, which has been largely neglected currently. The cultural background of both backers and fundraisers become salient for the reward-based crowdfunding for creative or artistic projects. Second, we investigate the role of geographic distance, aiming to resolve the inconsistent findings between the two schools. Third, by demonstrating the asymmetric effects of cultural and geographic distance on experiential and new backers, we empirically infer the social capital, in which the backers develop inside the crowdfunding community, as the plausible underlying mechanism. This differs but complements what Colombo et al. [31] postulated that the internal social capital project creators acquire in the crowdfunding platform helps attract contributions.

Notably, Burtch etal. [25] also examined the dual roles of geographic and cultural distance and evidence that backers do prefer culturally similar and geographically proximate project creators. We differ from it for at least two points. First, Burtch et al. [25] investigated the aggregated effects of geographic and cultural distance at the national level by aggregating all crowdfunding by country. We dig deeply at the individual project level and map out their effects on individual crowdfunding project attractiveness. Second, while Burtch et al. [25] proposed the IT-based trust to explain the adverse effects of geographic and cultural distance, we empirically show the social capital as one plausible explanation by uncovering the their asymmetric effects on experienced and new backers.
2.2. Crowdfunding Project Attractiveness. When confronting various crowdfunding projects on Kickstart.com, potential backers usually aim to tap the most attractive one and decide the contribution amount. Although crowdfunding seems to be a promising channel, not all projects are able to attract the desired amount of funding [3]. Thus, whether a project is successfully funded measures the overall attractiveness. Meanwhile, the average fund indicates backers' willingness to contribute.

\subsection{The Effect of Cultural Distance on Crowdfunding Project} Attractiveness. There are strong forces within nations to create and maintain a shared culture [32]. Cultural distance refers to the extent to which the shared norms and values in one country differ from those in another and is operationalized in terms of the six dimensions: power distance, avoidance of uncertainty, individualism vs. collectivism, masculinity vs. feminity, long-term orientation vs. shortterm normative orientation, and indulgence vs. restraint [33]. Online crowdfunding usually involves cross-border business transactions or interactions with different societal value systems [34]. Furthermore, because we particularly focus on the reward-based crowdfunding platforms for creative or artistic ideas, a backer's motivation to help others realize their creative ideas, instead of financial incentives, is generally more significant [16]. The backer selects the most appealing ideas based on the appreciation of the "innovative," "creative," or "artistic" nature of the funded products, among other project signals. As a result, the cultural backgrounds of both the creator and backers become salient for funding decisions (whether and how much to fund a creative idea). This is quite consistent with what Chua et al.' [35] content that cultural distance is one of three cultural characteristics particularly relevant in understanding creative ideas or solutions in a global context.

Nevertheless, cultural distance has received very limited discussion in crowdfunding literature. Exceptionally, Burtch et al. [25] demonstrated that cultural differences play a significant impeding role in crowd funders' decision-making. The authors interpret this as an awareness effect, suggesting that cultural differences are only relevant insofar as backers are aware of them. Although Mollick [1] focuses on geographic distance, the implications he suggests for its positive effect on crowdfunding success propose that culture may play a pivotal role especially for those projects that reflect the underlying cultural components of particular geographic areas. These existing studies reveal either a positive or a negative effect, a situation similar to international business research.

On the one hand, cultural familiarity theory holds that firms are less likely to invest in culturally distant countries and that cultural difference hampers multinational enterprises' performance when investing in culturally distant countries (e.g., [36, 37]). On the other hand, some researchers provide evidence that cross-border acquisitions in culturally distant countries tend to be more valuable as more diversified cultural integration helps enhance postacquisition performance [38] or that high cultural distance 
has been associated with low rates of joint venture failure [39]. In sum, pertinent literature has identified a doubleedged sword effect of cultural distance in cross-border business [40].

This article proposes a nonlinear, U-shape relationship between cultural distance and crowdfunding project attractiveness, which indicates that cultural distance exerts a negative effect on project attractiveness when it is relatively small or moderate and a positive effect when large enough. This contention is based on the notion that, when deciding the attractiveness of a project located in a culturally different country, backers make the tradeoff between the uncertainty and perceived creativity. When relatively small or moderate, cultural distance produces frictions and poses difficulties to some extent in understanding and interpreting the creative ideas in the crowdfunding projects. Meanwhile, the small cultural distance between somewhat similar cultures engenders low perceived creativity for a creative idea described by a crowdfunding project, that is, backers' evaluation of a creative idea tends to be constrained by the conventions and routines of their home culture. Cultural proximity could reduce lenders' reach for wider and untapped potential [26]. Thus, cultural distance exerts a detrimental effect on the project attractiveness when it is low or moderate.

However, we postulate a positive effect of cultural difference when it is large enough. When people perceive an object, the distance increases the uncertainty and gives people a broader space for imagination, thus producing a kind of beauty of distance. A crowdfunding project needs to gain sufficient attention and recognition to encourage the public to contribute [26]. When evaluating an idea from a strikingly different culture, backers face large comprehensive complexity and difficulties, which is supposed to hamper its attractiveness. However, being exposed to more culturally diverse ideas can increase the creative content of the mind [41], motivate individuals to perform more adeptly in creative insight tasks [42], and stimulate cultural learning to acquire new information and understand about the assumptions, beliefs, customs, norms, values, or language of another culture [27]. Global crowdfunding projects may contain more novel information for backers [26] and receive more support due to a high level of novelty [43]. Thus, we propose that cultural distance that is large enough exerts a positive effect on backers' judgment of crowdfunding project attractiveness.

H1: cultural distance has a U-shape relationship with the crowdfunding project attractiveness; it exerts a negative impact when it is relatively low but a positive impact when large enough on the success of crowdfunding project ( $\mathrm{H} 1 \mathrm{a})$ and on the average contribution amount of backers (H1b).

2.4. The Effect of Geographic Distance on Crowdfunding Project Attractiveness. The "flat world" hypothesis that crowdfunding projects are usually supported by the broad geographic dispersion of investors [24] gives rise to an interesting question "do crowdfunding platforms reduce market frictions associated with geographic distance?"
Several studies examine the effect of geographic distance on funding decisions and reveal mixed findings. The home bias that backers favor geographically approximate fundraisers exists for both the equity-based crowdfunding on Prospers [21] and reward-based crowdfunding on SellaBand [19]. Contrarily, Mollick [1] and Kang et al. [26] disclosed a positive effect of geographic distance, implying that crowdfunding not only relaxes geographic constraints but also activates other mechanisms. Mollick [1] demonstrates this positive effect when crowdfunding projects reflect the underlying cultural products of particular geographic areas. Moreover, Kang et al. [26] contend that larger geographic distance may enhance entrepreneurs' reach for wider and untapped potential, and their study reveals that further geographical distance led to higher funding. In sum, previous studies have not concluded whether and how geographic distance exerts a significant effect on crowdfunding success performance.

Since the Internet facilitates instant and inexpensive communication across large distances, the impact of geographical distance between project creators and backers on crowdfunding projects has tended to fade in the context of online e-commerce and a globalized economy. The Kickstarter platform has users all over the world and belongs to a group of investors interested in or relatively familiar with the cultural and artistic creative industries. Culture and art creative projects are based on their own cultural attributes, with a certain story and sentimentality, which easily attract the attention of backers. Therefore, a project that sounds attractive or creative will break through geographical distance and have a group of enthusiastic supporters worldwide. Therefore, we propose the hypothesis as follows:

$\mathrm{H} 2$ : geographic distance exerts an insignificant impact on crowdfunding performance. There will be no significant difference between large geographic distance and small geographic distance in crowdfunding project attractiveness.

2.5. Social Capital for Experienced (vs. New) Backers. We further contend that the social capital the backers acquire from their community participation on the crowdfunding platform may drive the complex effects of cultural and geographic distance. The social capital refers to "the sum of the actual and potential resources embedded within, available through, and derived from the social contacts of an individual or organization" [44]. Crowdfunding platforms are not only intermediaries of monetary transactions but also loci of social connections [31]. Online community members routinely help one another, often going to great lengths to volunteer and share their expertise and resources with other members even when there are no apparent benefits from doing so [45-47]. Consumers derive many benefits from online community participation, such as learning, problem-solving, and the opportunity to socialize and ward off loneliness [48]. Most of previous literature investigated social capital from the perspective of the creators and has found that creators' social capital (i.e., a creator's social network ties, obligations to fund other 
creators, and the shared meaning of the crowdfunding project between the creator and the backers) had significant effects on crowdfunding performance in both China and the US [49], but has underscored the role of backers' social capital $[26,31]$. The computer-mediated interactions occur among creators and backers of projects [50] and entail behaviors specific to crowdfunding communities [31].

By participating in the crowdfunding platform, backers can accumulate social capital in terms of information source and social support $[51,52]$. Thus, experienced backers are more able to make the complex tradeoff between the perceived uncertainty and creativity when evaluating the creative ideas. We empirically demonstrate this by the asymmetric effects of cultural and geographic distance on experienced vs. new backers. Cultural distance has a U-shape effect in attracting more experienced backers (but not new backers) to support the project. This is similar to research on the multicultural experience-creativity link that the more contacts among two intercultural individuals, the more likely they assimilate and draw upon ideas from both cultures to synthesize novel and useful insights [53]. Furthermore, we speculate that when the cultural distance is large enough, backers will obviously perceive that the project is different from the local culture of their own country. People with investment experience pursue novel psychological feelings and have the need to explore new things. Even if the cultural distance of the project is too large to lead to a certain degree of risk-taking, cultural distance will not be the reason to hinder their investment. Instead, the project uncertainty and risk-taking brought by cultural distance may become the attraction of their investment. Therefore, we propose the hypothesis as follows:

H3a: cultural distance has a U-shape effect in attracting the experienced backers; it exerts a negative impact on the number of the experienced backers when relatively small, but a positive impact when large enough.

New backers lack enough social capital and are less able to make connections between disparate ideas originating from different cultures. Furthermore, they are less likely to inspire creative thinking or break away from structured and routine ways of approaching problems. In order to adapt to cultural differences, new backers need to pay more physical and mental costs. Because many investors will encounter culture shock, when facing strange stimulus, people are easy to lose the basic ability to understand problems and even distinguish things and choose to escape and return. Therefore, we propose the hypothesis as follows:

H3b: cultural distance has no significant effect in attracting the new backers

The entry barrier for launching projects on crowdfunding platforms is very low, so most new backers are not competent to compare and optimize choices in so many projects. This challenge can enlarge information asymmetry between creators and backers in the crowdfunding markets [18]. Also, new backers lack the information resource or social support from the acquired social capital on the online platform, so they cannot accurately evaluate the potential benefits and risks of competing crowdfunding projects [11]. Therefore, preference for geographically proximate projects seems to be reasonable for naive backers. Therefore, we postulate that geographic distance exerts differential effects on experienced vs. new backers.

$\mathrm{H} 3 \mathrm{c}$ : whereas large geographic distance discourages the new backers from contributing, it encourages the experienced backers

\section{Methodology}

3.1. Sample. Kickstarter is the largest reward-based crowdfunding provider worldwide [28], and data from the platform have been used in several prior studies (e.g., $[1,6,10,14,31])$. Kickstarter is appropriate for this study because first, the "creative" or "artistic" nature of creative ideas described by Kickstarter projects makes different cultural backgrounds salient in appreciation and judgment. Second, Kickstarter presents all project information such as resident city, nationality, funding and fundraising history, the funds raised thus far, number of backers who have contributed, and the frequency distribution of the backers. Till August $17^{\text {th }} 2021$, its several million community members have pledged $\$ 6,033,885,042$ to fund 206,813 creative ideas. Among 20,068,256 total backers, $33.79 \%$ backers have backed two or more projects.

This study uses Python to collect the real data generated by creators and backers from kickstarter.com. Specifically, this study grabs the key fields of project which ended in 2017 and get the data of 264 fundraising projects, among which 175 succeeded and 89 failed.

3.2. Data Descriptions. We summarize in Table 1 the project characteristics for the whole sample and the successful and unsuccessful subsamples, respectively. The average fundraising cycle is 34 days, and those successful ones tend to have shorter cycles ( 32 vs. 37 days). On average, the projects receive funds $(\$ 189,77)$ much more than they request $(\$ 14,895)$. Those successful projects tend to receive more contributions $(\$ 26,477)$ than the requested amount $(\$ 11,027)$, while those unsuccessful ones usually set higher targets $(\$ 22,501)$ but receive much fewer contributions $(\$ 4,485)$.

For each project, the "community" section demonstrates the backers' composition, including the frequency distribution of backer origins and the number of new and experienced backers, respectively. The summary of cultural distance, geographic distance, and percentage of experienced backers are given in Table 1. The projects can appeal to the experienced backers a bit more (59\%). The focal variable we are interested in is the cultural distance between the creator and backers. Following Cho and Kim [54], we gauge the cultural distance between the creator and the top 10 countries (along with the number of backers from each of the 10 countries) based upon the six-dimension national culture model by Hofstede [33]. We aggregate the distance scores, which is weighted by the frequency of each country, 
TABLE 1: Statistical summary of the sample.

\begin{tabular}{|c|c|c|c|c|c|c|c|c|c|}
\hline & \multicolumn{3}{|c|}{ Total sample (264) } & \multicolumn{3}{|c|}{ Successful (175) } & \multicolumn{3}{|c|}{ Unsuccessful (89) } \\
\hline & Mean & Min. & Max. & Mean & Min. & Max. & Mean & Min. & Max. \\
\hline Fundraising cycle (day) & 34 & 7 & 379 & 32 & 7 & 61 & 37 & 10 & 379 \\
\hline Target (USD) & 14,895 & 1 & 165,000 & 11,027 & 1 & 160,000 & 22,501 & 400 & 165,000 \\
\hline Funded amount (USD) & 189,77 & 0 & 506,351 & 26,477 & 67 & 506,351 & 4,485 & 0 & 50,010 \\
\hline$\%$ of experienced backers & 0.59 & 0 & 1 & 0.59 & 0 & 1 & 0.57 & 0.05 & 1 \\
\hline Cultural distance & 55.84 & 42.13 & 69.8 & 55.66 & 42.13 & 62.95 & 56.24 & 53.20 & 69.8 \\
\hline Geographic distance $(\mathrm{km})$ & 2,962 & 8 & 13,082 & 2,905 & 15 & 13,082 & 3,090 & 8 & 9,637 \\
\hline
\end{tabular}

on six available dimensions (https://geert-hofstede.com/ cultural-survey.html). To measure the geographic distance between the creator and the top 10 cities, we use the interface of Google Maps APIs to obtain the latitudes and longitudes for each city. We manually measure the straight-line geographic distance for each pair of cities.

Besides the cultural and geographic distance, we include several essential covariates. The project duration, which indicates the degree of project exposure, offers for awareness and attention-building and promote the project performance [20]. The fundraising target usually set up a shared group goal among backers. When group identification is relatively weak (as in crowdfunding community with anonymous members), individuals decide to pursue the shared group goal if believed to be worthwhile. Thus, both the fundraising cycle and project target should play a role in crowdfunding decisions. Additionally, researchers have illustrated that the personal characteristics of creators lead to discriminations in the crowdfunding market $[12,55]$. The number of initiated projects and that of successfully funded ones of a particular creator usually indicate the sophistication of creators in the market and thus can influence the crowdfunding project attractiveness. All the relevant variables are defined in detail in Table 2.
3.3. Empirical Models and Results. To test the effect of cultural and geographic distance on crowding project attractiveness, we build a series of empirical models. Although we propose a quadratic relationship between the cultural distance and project attractiveness, we include the linear relationship as the baseline models.

\subsubsection{Effect of Cultural and Geographic Distance on} Crowdfunding Project Attractiveness. As Kickstarter adopts the rule of "All-or-Nothing" support, backers can successfully contribute to a project only when the requested amount has been reached. Thus, this article measures the crowdfunding project attractiveness by whether the project is successfully funded and average fund each backer invests. The regression models are shown in $\operatorname{model}^{1}$ and model $^{2}$, respectively. Particularly, as the dependent variable in model $^{1}$ is a dummy to indicate when a project is successfully funded (i.e., 1) or not (i.e., 0), we adopt the probit regression models. Please note that we also examine the linear relationship between the cultural and geographic distance and project attractiveness as the baseline models in model ${ }_{\text {baseline }}^{1}$ and model $_{\text {baseline }}^{2}$.

$$
\begin{aligned}
\operatorname{Prob}(\text { success })= & \alpha_{0}^{1}+\beta_{1}^{1} \text { culture distance }+\beta_{2}^{1} \text { culture distance }{ }^{2}+\beta_{3}^{1} \log (\text { geographic distance }) \\
& +\gamma_{1}^{1} \text { requested amount }+\gamma_{2}^{1} \text { fundraising cycle }+\gamma_{3}^{1} \text { historical projects } \\
& +\gamma_{4}^{1} \text { historical success } \\
& +\gamma_{5}^{1} \text { total backers }+\gamma_{6}^{1} \text { naive backers }+\varepsilon^{1}, \quad\left(\operatorname{model}^{1}\right)
\end{aligned}
$$

Average fund $=\alpha_{0}^{2}+\beta_{1}^{2}$ culture distance $+\beta_{2}^{2}$ culture ${ }^{2}+\beta_{3}^{2} \log ($ geographic distance $)$

$+\gamma_{1}^{2}$ requested amount $+\gamma_{2}^{2}$ fundraising cycle $+\gamma_{3}^{2}$ historical projects $+\gamma_{4}^{2}$ historical success

$+\gamma_{5}^{2}$ total backers $+\gamma_{6}^{2}$ naive backers $+\varepsilon^{2}, \quad\left(\right.$ model $\left.^{2}\right)$.

As displayed in the first column of Table 3, the cultural distance $\left(-.132^{* *}, \mathrm{SE}=0.054\right)$ does not have a significant linear effect on crowdfunding project success. However, the estimation results for the quadratic relationships shown in the second column reveal that the cultural distance has a significant $\mathrm{U}$-shape relationship with the crowdfunding success $\left(-1.453^{* *}, \mathrm{SE}=0.703 ; 0.012^{* *}, \mathrm{SE}=0.006\right)$. When the cultural distance is relatively small, the larger the average cultural distance between the backers and the project creator, the less attractive the artistic crowdfunding project, and thus the lower the success likelihood. When the cultural distance is large to some extent, the more culturally distant projects become more appealing and are more likely to succeed. Nevertheless, the geographic distance does not 
TABLE 2: Definitions of the variables.

\begin{tabular}{|c|c|c|}
\hline Variables & Type and unit & Definition \\
\hline \multicolumn{3}{|l|}{ Dependent variables } \\
\hline Success or failure & Dummy coded & 1 if a project succeeds and 0 otherwise \\
\hline Average fund & $\begin{array}{l}\text { Ratio variable; } \\
\text { USD }\end{array}$ & $\begin{array}{l}\text { The average amount per backer contributes for a particular project, calculated by the } \\
\text { total amount a project raises divided by the number of total backers }\end{array}$ \\
\hline $\begin{array}{l}\text { The number of } \\
\text { experienced backers }\end{array}$ & Counting variable & The number of experienced backers funding a particular project \\
\hline $\begin{array}{l}\text { The number of new } \\
\text { backers }\end{array}$ & Counting variable & The number of new backers funding a particular project \\
\hline \multicolumn{3}{|l|}{ Independent variables } \\
\hline Cultural distance & Ratio variable & $\begin{array}{l}\text { The average cultural distance between the creator and the funding backers based on the } \\
\text { six-dimension culture model }\end{array}$ \\
\hline Geographic distance & $\begin{array}{l}\text { Ratio variable; } \\
\text { kilometer. }\end{array}$ & $\begin{array}{l}\text { The average geographic distance between the creator and the funding backers based on } \\
\text { the Google Maps APIs }\end{array}$ \\
\hline \multicolumn{3}{|r|}{ 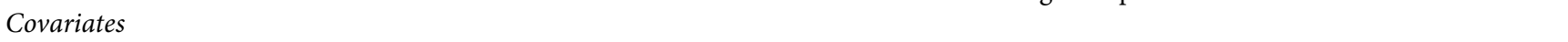 } \\
\hline $\begin{array}{l}\text { The number of total } \\
\text { backers }\end{array}$ & Counting variable & The number of total backers funding a particular project \\
\hline Requested amount & $\begin{array}{c}\text { Ratio variable; } \\
\text { USD }\end{array}$ & The specified amount a creator requests for the initiated project \\
\hline Fundraising cycle & Ratio variable; day. & The specified days for fundraising \\
\hline Historical projects & Counting variable & The number of projects a creator previous initiated \\
\hline Historical success & Counting variable & The number of successful projects previously initiated by a creator \\
\hline
\end{tabular}

${ }^{a}$ The number of total backers and the number of naïve backers included as control variables in the regressions on project attractiveness.

TABLE 3: The effects of cultural and geographic distance on crowdfunding project attractiveness.

\begin{tabular}{|c|c|c|c|c|}
\hline \multirow[b]{3}{*}{ C 1 to diono } & Model $_{\text {baseline }}^{1}$ & \multirow{2}{*}{ or failure Model $^{1}$} & \multirow{2}{*}{\multicolumn{2}{|c|}{$\begin{array}{l}\text { Model }_{\text {baseline }}^{2} \text { Model }^{2} \\
\text { DV, the average fund per backer }\end{array}$}} \\
\hline & DV, success or failure & & & \\
\hline & $-0.131^{* *}(0.054)$ & $-1.446^{*}(0.813)$ & $-7.397(5.781)$ & $-241.640^{* * *}(67.189)$ \\
\hline Cultural distance ${ }^{2}$ & - & $0.0113^{* *}(0.562)$ & - & $2.087^{* * *}(0.596)$ \\
\hline Log (geographic distance) & $-0.023(0.099)$ & $-0.030(0.099)$ & $3.871(10.043)$ & $6.326(9.839)$ \\
\hline Requested amount & $-3.93 \hat{e}(-5)^{* * *}(7.10 \hat{e}(-6))$ & $-4.33 \hat{e}(-5)^{* * *}(8.25 \hat{e}(-6))$ & $0.004^{* * *}(0.0005)$ & $0.004^{* * *}(0.0005)$ \\
\hline Fundraising cycle & $-0.006(0.005)$ & $-0.006(0.005)$ & $-0.001(0.512)$ & $-0.219(0.500)$ \\
\hline Historical projects & $0.185^{*}(0.086)$ & $0.176^{* *}(0.086)$ & $-0.322(3.045)$ & $-0.219(2.975)$ \\
\hline Historical success & $0.011(0.009)$ & $0.011(0.009)$ & $-0.150(0.325)$ & $-0.109(0.318)$ \\
\hline Total backers & $0.004^{* *}(0.002)$ & $0.005^{* *}(0.002)$ & $-0.085^{*}(0.044)$ & $-0.077^{*}(0.043)$ \\
\hline New backers & $0.033^{* * *}(0.008)$ & $0.032^{* * *}(0.008)$ & $0.047(0.113)$ & $-0.030(0.111)$ \\
\hline \multirow[t]{3}{*}{ Constant } & $7.356(3.271)$ & $45.606(29.291)$ & $459.033(340.880)$ & $7002.579^{* * *}(1899.579)$ \\
\hline & Prob $>$ chi $^{2}=0.000$ & Prob $>$ chi $^{2}=0.000$ & Adjusted $R^{2}=0.170$ & Adjusted $R^{2}=0.2067$ \\
\hline & Pseudo $R^{2}=0.385$ & Pseudo $R^{2}=0.390$ & Adjusted $K^{-}=0.1 / 0$ & Aajusted $R^{-}=0.206 /$ \\
\hline
\end{tabular}

${ }^{* * *}$ Significant at $0.01 .{ }^{* *}$ Significant at $0.05 .{ }^{*}$ Significant at 0.10 .

exert any significant effect on the success probability of crowdfunding projects either in model $_{\text {baseline }}^{1}(-0.022$, $\mathrm{SE}=0.099)$ or in $\operatorname{model}^{1}(-0.029, \mathrm{SE}=0.100)$.

The last two columns of Table 3 also reveal how the cultural and geographic distance influence the backers' decisions of contribution amount. Similarly, although the cultural distance does not show a significant effect $(-7.402$, $\mathrm{SE}=5.777)$ on the average contributed amount in the baseline model (model $\mathrm{baseline}^{2}$ ), it demonstrates a significant $\mathrm{U}$-shape impact in the quadratic relationship $\left(-240.606^{* * *}\right.$, $\left.\mathrm{SE}=67.149 ; 2.078^{* * *}, \mathrm{SE}=0.596\right)$. When the cultural distance between the backers and project creator is moderate, the backers may perceive the project to be less creative and less attractive due to the somewhat similar cultures and thus be more reluctant to contribute. Therefore, the attractiveness of artistic crowdfunding project is negatively related to the cultural distance. The result was in accord with Kang et al.' [26] contention and support H1a. However, when the cultural distance is large enough, backers are exposed to the information which is brand new or strikingly different from the conventions and routines of their home culture. Accordingly, they may consider the crowdfunding project to be eye catching and innovative and pay more attention to the project, rendering them to contribute considerable funds. Therefore, H1b is support. Again, the geographic distance does not exert any significant effect on the average amount a backer is willing to contribute either in model baseline $^{2}$ (4.367, $\mathrm{SE}=10.018)$ or in $\operatorname{model}^{2}(6.836, \mathrm{SE}=9.817)$. 
3.3.2. Effect of Cultural and Geographic Distance on Experienced vs. New Backers. We postulate that the social capital the backers acquire from their community participation of crowdfunding platform is one of the plausible mechanisms that may explain the effects of cultural distance. We empirically disclose this potential by investigating the asymmetric effects of cultural distance on experienced vs. new backers. Meanwhile, we investigate whether geographic distance shows any significant effect on experienced vs. new backers. For comparison purpose, we add the model for their impact on the total number of backers as well. On Kickstarter, each project discloses not only the frequency distribution of backer origins but also the number of new backers and that of experienced backers. As the three dependent variables are counting variables, the negative binomial regression modes are employed in model $^{3}$, model $^{4}$, and model $^{5}$ (as well as their baseline models) as follows:

$$
\begin{aligned}
\text { The total number of backers }= & \alpha_{0}^{3}+\beta_{1}^{3} \text { culture distance }+\beta_{2}^{3} \text { culture distance }{ }^{2}+\beta_{3}^{3} \log (\text { geographic distance }) \\
& +\gamma_{1}^{3} \text { requested amount }+\gamma_{2}^{3} \text { fundraising cycle }+\gamma_{3}^{3} \text { historical projects }+\gamma_{4}^{3} \text { historical success } \\
& +\gamma_{5}^{3} \text { total backers }+\gamma_{6}^{3} \text { naive backers }+\varepsilon^{3}, \quad\left(\text { model }^{3}\right) . \\
& \text { The number of experienced backers }=\alpha_{0}^{4}+\beta_{1}^{4} \text { culture distance }+\beta_{2}^{4} \text { culture distance }{ }^{2} \\
& +\beta_{3}^{4} \log (\text { geographic distance })+\gamma_{1}^{4} \text { requested amount }+\gamma_{2}^{4} \text { fundraising cycle } \\
& +\gamma_{3}^{4} \text { historical projects }+\gamma_{4}^{4} \text { historical success }+\gamma_{5}^{4} \text { total backers }+\gamma_{6}^{4} \text { naive backers }+\varepsilon^{4}, \quad\left(\text { model }{ }^{4}\right) . \\
& \alpha_{0}^{5}+\beta_{1}^{5} \text { culture distance }+\beta_{2}^{5} \text { culture distance }{ }^{2}+\beta_{3}^{5} \log (\text { geographic distance }) \\
& +\gamma_{1}^{5} \text { requested amount }+\gamma_{2}^{5} \text { fundraising cycle }+\gamma_{3}^{5} \text { historical projects }+\gamma_{4}^{5} \text { historical success } \\
& +\gamma_{5}^{5} \text { total backers }+\gamma_{6}^{5} \text { naive backers }+\varepsilon^{5}, \quad\left(\text { model }{ }^{5}\right) .
\end{aligned}
$$

The estimation results for model ${ }^{3}$, model $^{4}$, and $\operatorname{model}^{5}$ as well as their baseline models are given in Table 4 . The cultural distance does not exert a significant effect on the total number of backers either in the linear form in model $_{\text {baseline }}^{3}(-0.063, \mathrm{SE}=0.042)$ or in the quadratic form in $\operatorname{model}^{3}(-0.465, \mathrm{SE}=0.563 ;-4.64 \hat{e}(-3), \mathrm{SE}=4.95 \hat{e}(-3))$. Surprisingly, the geographic distance manifests a significant positive effect in attracting more backers to contribute (0.226, $\mathrm{SE}=0.059)$. This result is consistent with what Mollick [1] and Kang et al. [26] advocate but contradicts with the negative effect identified by Lin and Viswanathan [21] and Burtch et al. [25].

To empirically infer the social capital the backers acquire from community interactions as the underlying mechanism, the aforementioned effects of cultural distance should be further qualified by their asymmetric effects on the new and experienced backers. As indicated by the fifth and seventh columns, the U-shape relationship exists of the cultural distance only for the experienced backers $\left(-0.991^{* *}, \mathrm{SE}=0.341 ; .009^{* * *}, \mathrm{SE}=0.003\right)$ but does not for the new backers $(-0.065, \mathrm{SE}=0.379$; $-5.36 \hat{e}(-4), \mathrm{SE}=3.43 \hat{e}(-3))$. The asymmetric impacts of cultural distance on the experience vs. new backers are intriguing. It may imply that, for it to play a significant role in funding decisions, culture distance should become salient. Our findings disclose that, only if backers acquire social capital from the platform interactions and become experienced in evaluating the attractiveness of creative ideas, they are more likely to be able to make the complex tradeoff between the uncertainty and perceived creativity engendered by cultural distance.

Interestingly, geographic distance exerts a negative effect in attracting the naive backers $\left(-0.323^{* * *}, \mathrm{SE}=0.054\right)$ but a positive effect in attracting experienced backers $\left(0.137^{* * *}\right.$, $\mathrm{SE}=0.045$ ). Large geographic distance discourages the backers who seldom have contributing experience on Kickstarter, probably because the lack of a common set of beliefs and expression systems hampers the communication and understanding between each other, reducing the uncertainty of cooperation. Also, small distance indicates a low cost of project knowledge search and acquisition, but large distance could increase the cost of cooperation and innovation through increased communication time and traffic distance. Therefore, naive backers are more likely to contribute to the crowdfunding projects initiated by geographically proximate creators.

However, for those experienced backers, they have benefited from online community participation and accumulated social capital from their previous contributions and they believe online community members from different countries or areas would help each other. Therefore, trust and knowledge exchange of experienced backers are not constrained by geographic distance; they would not consider geographic distance convenience as the most important factor, but focus on the benefit of social capital brought by far project rather than nearby projects. Also, excessive proximity could reduce the learning range from each other, so they reduce innovation enthusiasm. Thus, those experienced backers are more attracted by the creative ideas 
TABLE 4: The effect of cultural and geographic distance on backer composition.

\begin{tabular}{|c|c|c|c|c|c|c|}
\hline & \multicolumn{2}{|c|}{ DV, the total number of backers } & $\mathrm{DV}$, the number of experienced backers & $\begin{array}{c}\text { Model }^{4} \\
\text { experienced backers }\end{array}$ & \multicolumn{2}{|c|}{ DV, the number of new backers } \\
\hline $\begin{array}{l}\text { Cultural } \\
\text { distance }\end{array}$ & $-0.062(0.042)$ & $-0.459(0.565)$ & $-0.048(0.041)$ & $-0.994^{* * *}(0.341)$ & $0.006(0.029)$ & $-0.063(0.381)$ \\
\hline $\begin{array}{l}\text { Cultural } \\
\text { distance }^{2}\end{array}$ & - & $\begin{array}{l}-4.58 \hat{e}(-3) \\
(4.97 \hat{e}(-3))\end{array}$ & - & $0.009^{* * *}(0.003)$ & - & $\begin{array}{l}-5.14 \hat{e}(-4) \\
(3.45 \hat{e}(-3))\end{array}$ \\
\hline $\begin{array}{l}\text { Log } \\
\text { (geographic } \\
\text { distance) }\end{array}$ & $0.235^{* * *}(0.059)$ & $0.227^{* * *}(0.059)$ & $0.147^{* * *}(0.046)$ & $0.140^{* * *}(0.045)$ & $-0.319^{* * *}(0.053)$ & $-0.321^{* * *}(0.054)$ \\
\hline $\begin{array}{l}\text { Requested } \\
\text { amount }\end{array}$ & $\begin{array}{c}2.76 \hat{e}(-5)^{* * *} \\
(5.09 \hat{e}(-6))\end{array}$ & $\begin{array}{c}2.79 \hat{e}(-5)^{* * *} \\
(5.14 \hat{e}(-6))\end{array}$ & $\begin{array}{l}4.72 \hat{e}(-6)^{*} \\
(2.57 \hat{e}(-6)) \\
\end{array}$ & $\begin{array}{l}5.04 \hat{e}(-6)^{*} \\
(2.59 \hat{e}(-6)) \\
\end{array}$ & $\begin{array}{c}9.84 \hat{e}(-6)^{* * *} \\
(3.52 \hat{e}(-6))\end{array}$ & $\begin{array}{c}9.91 \hat{e}(-6)^{* * *} \\
(3.56 \hat{e}(-6))\end{array}$ \\
\hline $\begin{array}{l}\text { Fundraising } \\
\text { cycle }\end{array}$ & $\begin{array}{l}-2.97 \hat{e}(-3) \\
(4.79 \hat{e}(-3))\end{array}$ & $\begin{array}{l}-2.62 \hat{e}(-3) \\
(4.94 \hat{e}(-3))\end{array}$ & $\begin{array}{l}-5.51 \hat{e}(-3) \\
(4.12 \hat{e}(-3)) \\
\end{array}$ & $\begin{array}{l}-5.63 \hat{e}(-3) \\
(4.00 \hat{e}(-3)) \\
\end{array}$ & $\begin{array}{c}3.14 \hat{e}(-3) \\
(3.26 \hat{e}(-3))\end{array}$ & $\begin{array}{c}3.15 \hat{e}(-3) \\
(3.26 \hat{e}(-3))\end{array}$ \\
\hline $\begin{array}{l}\text { Historical } \\
\text { projects }\end{array}$ & $\begin{array}{c}8.66 \hat{e}(-4) \\
(1.50 \hat{e}(-2))\end{array}$ & $7.24 \hat{e}(-4)(0.015)$ & $0.052^{* *}(0.023)$ & $0.052^{* *}(0.023)$ & $-0.014(0.011)$ & $-0.014(0.011)$ \\
\hline $\begin{array}{l}\text { Historical } \\
\text { success }\end{array}$ & $\begin{array}{c}1.16 \hat{e}(-3) \\
(2.39 \hat{e}(-3))\end{array}$ & $\begin{array}{c}1.16 \hat{e}(-3) \\
(2.38 \hat{e}(-3))\end{array}$ & $\begin{array}{l}4.26 \hat{e}(-3)^{*} \\
(2.30 \hat{e}(-3))\end{array}$ & $\begin{array}{l}4.09 \hat{e}(-3)^{*} \\
(2.24 \hat{e}(-3))\end{array}$ & $\begin{array}{c}-4.10 \hat{e}(-3)^{* * *} \\
(1.52 \hat{e}(-3))\end{array}$ & $\begin{array}{c}-4.10 \hat{e}(-3)^{* * *} \\
(1.52 \hat{e}(-3))\end{array}$ \\
\hline $\begin{array}{l}\text { Total }{ }^{\#} \text { of } \\
\text { backers }\end{array}$ & - & - & $\begin{array}{c}2.77 \hat{e}(-3)^{* * *} \\
(3.00 \hat{e}(-4))\end{array}$ & $\begin{array}{c}2.74 \hat{e}(-3)^{* * *} \\
(2.97 \hat{e}(-4))\end{array}$ & $\begin{array}{c}1.96 \hat{e}(-3)^{* * *} \\
(2.27 \hat{e}(-4))\end{array}$ & $\begin{array}{c}1.96 \hat{e}(-3)^{* * *} \\
(2.27 \hat{e}(-4))\end{array}$ \\
\hline Constant & $6.430^{* * *}(2.512)$ & $-8.320(16.044)$ & $5.112^{* *}(2.328)$ & $-24.35^{* *}(9.71)$ & $4.898^{* * *}(1.692)$ & $3.351(10.488)$ \\
\hline & $\begin{array}{l}\text { Prob }>\mathrm{chi}^{2}=0.000 \\
\text { Pseudo } R^{2}=0.0291\end{array}$ & $\begin{array}{l}\text { Prob }>\text { chi }^{2}=0.000 \\
\text { Pseudo } R^{2}=0.0294\end{array}$ & $\begin{array}{l}\text { Prob }>\text { chi }^{2}=0.000 \\
\text { Pseudo } R^{2}=0.1037\end{array}$ & $\begin{array}{l}\text { Prob }>\text { chi }^{2}=0.000 \\
\text { Pseudo } R^{2}=0.1061\end{array}$ & $\begin{array}{l}\text { Prob }>\text { chi }^{2}=0.000 \\
\text { Pseudo } R^{2}=0.1032\end{array}$ & $\begin{array}{l}\text { Prob }>\text { chi }^{2}=0.000 \\
\text { Pseudo } R^{2}=0.1035\end{array}$ \\
\hline
\end{tabular}

${ }^{* * *}$ Significant at $0.01 .{ }^{* *}$ Significant at $0.05 .{ }^{*}$ Significant at 0.10 .

proposed by geographically distant creators. Therefore, the discussions on the asymmetric effects of geographic distance enrich the understanding of the effect of geographic distance in the debating literature and empirically advocate the social capital as the plausible mechanism.

\section{Discussion and Conclusions}

By using a sample of 264 crowdfunding projects on Kickstarter. com, this study investigates the impact of cultural and geographic distance on crowdfunding performance and unveils several exciting findings. First, cultural distance exerts a U-shape effect, which initially impedes the crowdfunding performance but promotes projects when large enough. Specifically, cultural distance exerts a negative impact when it is relatively low but a positive impact when large enough on the success of crowdfunding project and the average contribution amount of backers. Second, this study reveals that geographic distance exerts an insignificant impact on either project success or the average contribution amount. Third, cultural and geographic distance exerts the asymmetric effects on experienced versus new backers. Cultural distance has a U-shape effect in attracting experienced backers, but no effect in attracting new backers. But projects with large geographic distance appeal to the experienced backers but discourage new backers from contributing.

4.1. Theoretical Contributions. This study differs from prior research along several vital dimensions. First, it is one of the scarce studies to understand the implications of cultural distance on reward-based crowdfunding thoroughly. In crowdfunding, transactions are mediated on platforms which increase information asymmetry between backers and the creators. Backers evaluate the information provided by the creators and contribute more if the creator delivers more valuable signals that alleviate information asymmetry. The primary literature focuses on the project quality signals [e.g., [7]], creator-trustworthiness signals [e.g., [8]] or social influence during the dynamic fundraising cycle [e.g., [5]], but ignores the role of cultural distance [25].

Different from the only two existing studies on cultural distance [i.e., [1, 25]], the U-shape relationship between the cultural distance and crowdfunding performance are original and creative to the crowdfunding literature, and backers' complicated tradeoff between uncertainty and perceived creativity drives the U-shape effect. When evaluating a project from a similar culture, backers tend to reduce the imagination of potential, pay more attention to the ambiguity, and thus feel not so attractive. When evaluating a project embodying some characteristics of different cultures, backers tend to pay particular attention to the project and inspire the creative content of the mind. Thus, their perceived creativity overcomes the uncertainty engendered.

Second, this study responds to previous disputes on geographic distance effect and reveals the complex effects of distance on crowdfunding. Rather than the "home bias" proposition [21], this study supports the "flat world" hypothesis [24] and shows that geographic distance does not significantly affect project success or average contribution amount. Noticeably, geographic distance implicitly influences the backer composition by successfully encouraging experienced backers' investment but discourages new backers.

Third, our findings offer new avenues for research toward understanding how cultural and geographic distance determines our choices and actions. This study innovatively 
and empirically infers the social capital as one plausible mechanism for the effects of cultural and geographic distance by showing the asymmetric effects on experienced versus new backers, while previous literature ignores how cultural distance and geographic distance influence the backer composition. The social capital that experienced backers acquired and accumulated from the Internet-mediated interactions $[26,31]$ helps reduce the uncertainty of the project and synthesize novel and useful insights. Therefore, experienced backers are more able to formulate funding decisions by balancing the uncertainty and perceived creativity. Contrarily, due to the lack of experience or social connections on the platform, new backers may feel difficult to communicate or assimilate essentially different ideas originating from different cultures. Furthermore, naïve bakers are less likely to get rid of rigid and fixed thinking way. Home bias exists in their decision-making process, making them show a local preference.

4.2. Practical Implications. From a practical point of view, creators can make use of the U-shape effect of cultural distance to adjust the pledging and project characteristics to increase the chance that a project is successfully funded. Creators should construct project descriptions of cultural distance to meet the needs of experienced backers. Based on the profile data (e.g., funding experience, background cultures, or geographic areas in this study), creators may disclose information (e.g., the number of Facebook connections, backers with similar interest), which help to influence the other signals sent in context of the project campaign. Creators could present the high degree of cultural distance by demonstrating the cultural diversity by photos or videos. The relevant and detailed textual descriptions or media content of projects can signal preparedness and seriousness to potential investors [56].

Second, both crowdfunding platforms and project creators should enhance Internet-mediated interactions to cultivate social capital for backers, which help them overcome the fractions caused by cultural and geographic distance. Social capital investment is a long-term process; therefore, creators may link the project to social media platforms such as Facebook or LinkedIn and actively interact with potential backers via two-way communication on Kickstarter to interact with potential backers to promote the project. The platform should encourage community participation, supporting backers in sharing, learning, problemsolving, and the opportunity to socialize. Besides, to attract experienced investors, creators may highlight the geographical distance of the project and set the distance unit to meters instead of kilometers when displaying the project description. However, to attract new backers, creators may weaken the geographical distance of the project when displaying the project, such as reducing the number used to indicate the distance.

Third, creators especially from start-up firms can use the Internet as a channel to promote their projects regardless of geographic distance. Internet gives potential backers the chance to process relevant information for the investment decision at a low cost, while also providing an opportunity to chat with creators. It is for this reason that creators should consider crowdfunding as a resource to cost-effectively bridge geographic boundaries and link investment opportunities.

4.3. Limitations and Future Research Directions. This study unavoidably suffers from several limitations that open avenues for further research. First, while the cultural background of bakers and creators becomes salient for rewardbased crowdfunding for artistic projects, the main findings need caution when generalizing to other types of projects (e.g. fast-moving consumer goods and luxury goods). Second, using data from reward-based crowdfunding raises concerns about the generalizability of our findings; thus, future research may collect data from multiple platforms. Third, although we used econometric models to empirically infer that the social capital experienced backers acquire from their previous platform participation drives the asymmetric effects of both cultural and geographic distance; further research may replicate this study in a more controlled experiment.

\section{Data Availability}

The data used to support the findings of this study are available from the corresponding author upon request.

\section{Conflicts of Interest}

The authors declare that there are no conflicts of interest.

\section{Acknowledgments}

This research was funded by Humanities and Social Sciences Research Projects of Anhui Province (SK2019A0698) and Talent Research Projects of Hefei University (20RC74).

\section{References}

[1] E. Mollick, "The dynamics of crowdfunding: an exploratory study," Journal of Business Venturing, vol. 29, no. 1, pp. 1-16, 2014.

[2] T. Hildebrand, M. Puri, and J. Rocholl, "Adverse incentives in crowdfunding," Management Science, vol. 63, no. 3, pp. 587-900, 2016.

[3] J. Hollas, "Is crowdfunding now a threat to traditional finance?" Corporate Finance Review, vol. 18, no. 1, p. 27, 2013.

[4] C. Courtney, S. Dutta, and Y. Li, "Resolving information asymmetry: signaling, endorsement, and crowdfunding success," Entrepreneurship: Theory and Practice, vol. 41, no. 2, pp. 265-290, 2017.

[5] J. Zhang and P. Liu, "Rational herding in microloan markets," Management Science, vol. 58, no. 5, pp. 892-912, 2012.

[6] N. Steigenberger and H. Wilhelm, "Extending signaling theory to rhetorical signals: evidence from crowdfunding," Organization Science, vol. 29, no. 3, pp. 529-546, 2018.

[7] S. Bi, Z. Liu, and K. Usman, "The influence of online information on investing decisions of reward-based crowdfunding," Journal of Business Research, vol. 71, pp. 10-18, 2017. 
[8] R. Iyer, A. I. Khwaja, E. F. P. Luttmer, and K. Shue, "Screening peers softly: inferring the quality of small borrowers," Management Science, vol. 62, no. 6, pp. 1554-1577, 2016.

[9] J. Michels, "Do unverifiable disclosures matter? evidence from peer-to-peer lending," The Accounting Review, vol. 87, no. 4, pp. 1385-1413, 2012.

[10] A. Parhankangas and M. Renko, "Linguistic style and crowdfunding success among social and commercial entrepreneurs," Journal of Business Venturing, vol. 32, no. 2, pp. 215-236, 2017.

[11] G. K. C. Ahlers, D. Cumming, C. Günther, and D. Schweizer, "Signaling in equity crowdfunding," Entrepreneurship: Theory and Practice, vol. 39, no. 4, pp. 955-980, 2015.

[12] M. Lin, N. R. Prabhala, and S. Viswanathan, "Judging borrowers by the company they keep: friendship networks and information asymmetry in online peer-to-peer lending," Management Science, vol. 59, no. 1, pp. 17-35, 2013.

[13] J. Duarte, S. Siegel, and L. Young, "Trust and credit: the role of appearance in peer-to-peer lending," Review of Financial Studies, vol. 25, no. 8, pp. 2455-2484, 2012.

[14] T. H. Allison, B. C. Davis, J. W. Webb, and J. C. Short, "Persuasion in crowdfunding: an elaboration likelihood model of crowdfunding performance," Journal of Business Venturing, vol. 32, no. 6, pp. 707-725, 2017.

[15] J. Cox, T. Nguyen, A. Thorpe, A. Ishizaka, S. Chakhar, and L. Meech, "Being seen to care: the relationship between selfpresentation and contributions to online pro-social crowdfunding campaigns," Computers in Human Behavior, vol. 83, pp. 45-55, 2018.

[16] V. Kuppuswamy and B. L. Bayus, "Does my contribution to your crowdfunding project matter?" Journal of Business Venturing, vol. 32, no. 1, pp. 72-89, 2017.

[17] B. C. Davis, K. M. Hmieleski, J. W. Webb, and J. E. Coombs, 'Funders' positive affective reactions to entrepreneurs' crowdfunding pitches: the influence of perceived product creativity and entrepreneurial passion," Journal of Business Venturing, vol. 32, no. 1, pp. 90-106, 2017.

[18] N. Wang, Q. Li, H. Liang, T. Ye, and S. Ge, "Understanding the importance of interaction between creators and backers in crowdfunding success," Electronic Commerce Research and Applications, vol. 27, pp. 106-117, 2018.

[19] A. Agrawal, C. Catalini, and A. Goldfarb, "Crowdfunding: geography, social networks, and the timing of investment decisions," Journal of Economics and Management Strategy, vol. 24, no. 2, pp. 253-274, 2015.

[20] G. Burtch, A. Ghose, and S. Wattal, "An empirical examination of the antecedents and consequences of contribution patterns in crowd-funded markets," Information Systems Research, vol. 24, no. 3, pp. 499-519, 2013.

[21] M. Lin and S. Viswanathan, "Home bias in online investments: an empirical study of an online crowdfunding market," Management Science, vol. 62, no. 5, pp. 1393-1414, 2016.

[22] S. Lai and M. Teo, "Home-biased analysts in emerging markets," Journal of Financial and Quantitative Analysis, vol. 43, no. 3, pp. 685-716, 2008.

[23] N. Strong and X. Xu, "Understanding the equity home bias: evidence from survey data," The Review of Economics and Statistics, vol. 85, no. 2, pp. 307-312, 2003.

[24] A. Agrawal, C. Catalini, and A. Goldfarb, "Friends, family, and the flat world: the geography of crowdfunding," NBER Working Paper, vol. 16820, pp. 1-61, 2011.

[25] G. Burtch, A. Ghose, A. Ghose, and S. Wattal, "Cultural differences and geography as determinants of online prosocial lending," MIS Quarterly, vol. 38, no. 3, pp. 773-794, 2014.
[26] L. Kang, Q. Jiang, and C.-H. Tan, "Remarkable advocates: an investigation of geographic distance and social capital for crowdfunding," Information \& Management, vol. 54, no. 3, pp. 336-348, 2017.

[27] J. G. Lu, A. C. Hafenbrack, P. W. Eastwick, D. J. Wang, W. W. Maddux, and A. D. Galinsky, "“Going out” of the box: close intercultural friendships and romantic relationships spark creativity, workplace innovation, and entrepreneurship," Journal of Applied Psychology, vol. 102, no. 7, pp. 1091-1108, 2017.

[28] E. Mollick and R. Nanda, "Wisdom or madness? comparing crowds with expert evaluation in funding the arts," Management Science, vol. 62, no. 6, pp. 1533-1553, 2015.

[29] P. Belleflamme, T. Lambert, and A. Schwienbacher, "Crowdfunding: tapping the right crowd," Journal of Business Venturing, vol. 29, no. 5, pp. 585-609, 2014.

[30] J.-A. Koch and M. Siering, "The recipe of successful crowdfunding campaigns," Electronic Markets, vol. 29, no. 4, pp. 661-679, 2019.

[31] M. G. Colombo, C. Franzoni, and C. Rossi-Lamastra, "Internal social capital and the attraction of early contributions in crowdfunding," Entrepreneurship: Theory and Practice, vol. 39, no. 1, pp. 75-100, 2015.

[32] G. Hofstede, G. J. Hofstede, and M. Minkov, Cultures and Organizations: Software of the Mind, McGraw-Hill, New York, NY, USA, 2010.

[33] G. Hofstede, Culture's Consequences: Comparing Values, Behaviors, Institutions and Organizations Across Nations, Sage Publications, Thousand Oaks, CA, USA, 2001.

[34] L. Tihanyi, D. A. Griffith, and C. J. Russell, "The effect of cultural distance on entry mode choice, international diversification, and MNE performance: a meta-analysis," Journal of International Business Studies, vol. 36, no. 3, pp. 270-283, 2005.

[35] R. Y. J. Chua, Y. Roth, and J.-F. Lemoine, "The impact of culture on creativity," Administrative Science Quarterly, vol. 60, no. 2, pp. 189-227, 2015.

[36] S.-H. Lee, O. Shenkar, and J. Li, "Cultural distance, investment flow, and control in cross-border cooperation," Strategic Management Journal, vol. 29, no. 10, pp. 1117-1125, 2008.

[37] Y. Luo and M. W. Peng, "Learning to compete in a transition economy: experience, environment, and performance," Journal of International Business Studies, vol. 30, no. 2, pp. 269-295, 1999.

[38] P. Morosini, S. Shane, and H. Singh, "National cultural distance and cross-border acquisition performance," Journal of International Business Studies, vol. 29, no. 1, pp. 137-158, 1998.

[39] S. H. Park and G. R. Ungson, "The effect of national culture, organizational complementarity, and economic motivation on joint venture dissolution," Academy of Management Journal, vol. 40, no. 2, pp. 279-307, 1997.

[40] T. H. Reus and B. T. Lamont, "The double-edged sword of cultural distance in international acquisitions," Journal of International Business Studies, vol. 40, no. 8, pp. 1298-1316, 2009.

[41] W. W. Maddux and A. D. Galinsky, "Cultural borders and mental barriers: the relationship between living abroad and creativity," Journal of Personality and Social Psychology, vol. 96, no. 5, pp. 1047-1061, 2009.

[42] C.-Y. Cheng and A. K.-Y. Leung, "Revisiting the multicultural experience-creativity link," Social Psychological and Personality Science, vol. 4, no. 4, pp. 475-482, 2013. 
[43] M. Schulz, P. Haas, K. Schulthess, I. Blohm, and J. M. Leimeister, "How idea creativity and hedonic value influence project success in crowdfunding," in Proceedings of the 12th International Conference On Wirtschaftsinformatik, Osnabrück, Germany, March 2015.

[44] J. Nahapiet and S. Ghoshal, "Social capital, intellectual capital, and the organizational advantage," Academy of Management Review, vol. 23, no. 2, pp. 242-266, 1998.

[45] M. Ma and R. Agarwal, "Through a glass darkly: information technology design, identity verification, and knowledge contribution in online communities," Information Systems Research, vol. 18, no. 1, pp. 42-67, 2007.

[46] F. Olivera, P. S. Goodman, and S. S.-L. Tan, "Contribution behaviors in distributed environments," MIS Quarterly, vol. 32, no. 1, pp. 23-42, 2008.

[47] M. M. Wasko and S. Faraj, "Why should i share? examining social capital and knowledge contribution in electronic networks of practice," MIS Quarterly, vol. 29, no. 1, pp. 35-57, 2005.

[48] N. Hara, "Online communities of practice: beyond organizational boundaries," Communities of Practice: Information Science and Knowledge Management, Springer, Berlin, Germany, 2009.

[49] H. Zheng, D. Li, J. Wu, and Y. Xu, "The role of multidimensional social capital in crowdfunding: a comparative study in China and US," Information \& Management, vol. 51, no. 4, pp. 488-496, 2014.

[50] S. Faraj and S. L. Johnson, "Network exchange patterns in online communities," Organization Science, vol. 22, no. 6, pp. 1464-1480, 2011.

[51] P. S. Adler and S.-W. Kwon, "Social capital: prospects for a new concept," Academy of Management Review, vol. 27, no. 1, pp. 17-40, 2002.

[52] C. Mathwick, C. Wiertz, and K. De Ruyter, "Social capital production in a virtual P3 community," Journal of Consumer Research, vol. 34, no. 6, pp. 832-849, 2008.

[53] A. K.-Y. Leung and C.-Y. Chiu, "Multicultural experience, idea receptiveness, and creativity," Journal of Cross-Cultural Psychology, vol. 41, no. 5-6, pp. 723-741, 2010.

[54] M. Cho and G. Kim, "A cross-cultural comparative analysis of crowdfunding projects in the United States and south Korea," Computers in Human Behavior, vol. 72, pp. 312-320, 2017.

[55] D. G. Pope and J. R. Sydnor, "What's in a picture?: evidence of discrimination from prosper.com," Journal of Human Resources, vol. 46, no. 1, pp. 53-92, 2011.

[56] A. Hoegen, D. M. Steininger, and D. Veit, "How do investors decide? an interdisciplinary review of decision-making in crowdfunding," Electronic Markets, vol. 28, no. 3, pp. 339-365, 2018. 